\title{
NOTE
}

\section{Synthesis and Properties of a High-Molecular-Weight Organosoluble Bisphenol A Novolac}

\author{
By Tadamasa NEMOTO, Isamu AMIR, and Gen-ichi KONISHI*
}

KEY WORDS: Novolac / Phenolic Resin / Addition-Condensation / Bisphenol A / Benzaldehyde / Naphthaldehyde / High-MolecularWeight Polymer /

Bisphenol A [2,2-bis(4-hydroxyphenyl)propane] has industrial significance as a precursor for epoxy resins $^{1,2}$ and polycarbonates (PCs). ${ }^{3,4}$ Epoxy resins are known as thermosetting, water- and chemical-resistant resins, and are often used in adhesives, coatings, and electronic circuit boards. On the other hand, polycarbonates, a class of one of the most well-known plastics in engineering, have excellent processability, thermal stability, and transparency; therefore, polymer materials based on bisphenol A have considerable potential. From this viewpoint, bisphenol A novolac is expected to reveal unique properties which are different from phenol novolac. ${ }^{5}$ Previously, Pan et al. reported addition-condensation of bisphenol A with formaldehyde or aromatic aldehydes; ${ }^{6}$ however, the preparation of bisphenol A-based novolacs with high molecular weights was not achieved $\left(M_{\mathrm{n}}: c a .800, M_{\mathrm{w}} / M_{\mathrm{n}}: c a .2 .00\right)$. In particular, in the case of addition-condensation of bisphenol A with formaldehyde, it was difficult to produce organosoluble novolacs because a lot of hydroxyl groups existed on the side chains, ${ }^{5}$ or the substrates were bonded via methylene units from formaldehyde. Bisphenol A and formaldehyde-based novolacs thus formed gels with network structures or lowmolecular-weight oligomers. It is very important to achieve an organosoluble novolac with a high molecular weight for the generation of a new type of bisphenol A-based novolac with good processability and higher heat-resistance. ${ }^{7}$ Such novolacs can also be expected to perform like an engineering plastic due to having the same type of PC.

In this paper, we describe the preparation, plus the thermal and solution properties of organosoluble bisphenol A novolacs with high molecular weights using aromatic aldehdyde. It is expected that the hydrophobicity, solubility in organic solvents, and molecular weights of the obtained polymers increase with the use of aromatic aldehdyde, and the thermal properties of the polymers can be modified. On the contrary, although methyl isobutyl ketone was used as a reaction solvent in a previous report, high-molecular-weight novolacs were obtained as described above. ${ }^{6}$ We focus on and utilize 2-methoxyethanol (a good solvent for bisphenol A novolac) as a reaction solvent in order to enhance the polymerization reaction and modify the solubility of the propagation species or products.

\section{EXPERIMENTAL}

\section{General}

Unless otherwise noted, all reagents and chemicals were used without further purification. Bisphenol A and paraformaldehyde (95\%) were obtained from Nacalai Tesque. All the ${ }^{1} \mathrm{H}$ NMR spectra and the ${ }^{13} \mathrm{C}$ NMR spectra were recorded by a $400 \mathrm{MHz}$ JEOL LNM-EX400 instrument with tetramethylsilane (TMS) as the internal standard. The FT-IR spectra were recorded using a JASCO FT-IR 460 plus spectrometer. Gel permeation chromatography (GPC) was carried out by a JASCO UV-2070 detector and a JASCO RI-2031 detector (TOSOH TSKgel $\mathrm{G}^{3} 000 \mathrm{H}_{\mathrm{XL}}$ or $\mathrm{G} 4000 \mathrm{H}_{\mathrm{XL}}$ column) using tetrahydrofuran (THF) as the eluent after calibration with polystyrene standards. Thermogravimetric analysis (TGA) was performed using a SII TG/DTA 6200 machine (SEIKO Instrument Inc.) with a heating rate of $10^{\circ} \mathrm{C} / \mathrm{min}$ under a nitrogen atmosphere. The solution properties of the obtained polymers were estimated by a Viscotek Triple Detector TDA302 system and its analysis program (Omni Sec3.0) according to our previous report. ${ }^{8}$ High Pressure Liquid Chromatography (HPLC) was carried out by the LC-9204 system with a JAI UV-3702 detector and JAI RI-50s detector (Shodex Column No. A410222).

\section{Addition-Condensation of Bisphenol-A with Various Alde- hydes}

The typical polymerization procedure is as follows (Scheme 1). To a $50 \mathrm{~mL}$ round bottom-flask, bisphenol $\mathrm{A}$ (5.0 mmol, $1.2 \mathrm{~g})$, aldehyde $(10 \mathrm{mmol})$ and 2-methoxyethanol $(4 \mathrm{~mL})$ were added in an open system. After the mixture was stirred for a while, conc. $\mathrm{H}_{2} \mathrm{SO}_{4}(0.2 \mathrm{~mL})$ was added at $0{ }^{\circ} \mathrm{C}$ slowly; then, the reaction mixture was stirred at $90^{\circ} \mathrm{C}$ for $1.5 \mathrm{~h}$. This mixture was poured into water to obtain the crude product. It was reprecipitated by $\mathrm{THF} /$ water or $\mathrm{THF} /$ methanol to give the objective product.

Benzaldehyde-based Novolac (1). Yield: $62 \%$ (reprecipitation with THF/water); ${ }^{1} \mathrm{H} \mathrm{NMR}\left(400 \mathrm{MHz}\right.$, acetone- $d_{6}, \delta(\mathrm{ppm})$ ): 0.81-1.53 (Ar-C $\left.\left(\mathrm{CH}_{3}\right)_{2}-\mathrm{Ar}\right), \quad 5.86-6.42$ (Ar-C $\left.\underline{H}(\mathrm{Ph})-\mathrm{Ar}\right)$, 


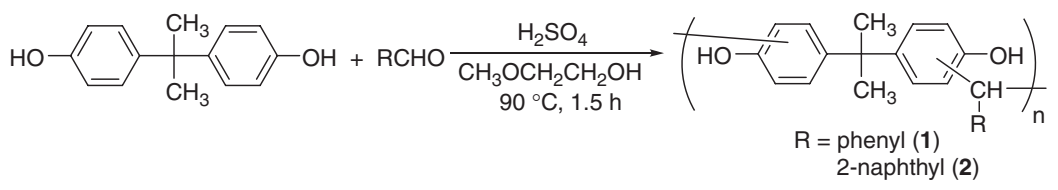

Scheme 1. Addition-condensation of bisphenol A with various aldehydes.

6.50-7.46 (aromatic $H$ ), 7.68-8.63 (Ph-OHH); ${ }^{13} \mathrm{C}$ NMR $\left(100 \mathrm{MHz}\right.$, acetone- $\left.d_{6}, \delta(\mathrm{ppm})\right): 30.8-33.3\left(-\mathrm{C}-\mathrm{CH}_{3}\right), 41.6-$ $42.7\left(\mathrm{Ar}-\underline{C}\left(\mathrm{CH}_{3}\right)_{2}-\mathrm{Ar}\right), 43.2-46.1(\mathrm{Ar}-\underline{C H}(\mathrm{Ph})-\mathrm{Ar}), 114.0-$ $116.5,125.0-127.2$, 127.2-129.3, 129.3-130.5, 130.5-131.8 (aromatic $\underline{C}$ without any functional groups, aromatic $\underline{C}-$ $\mathrm{CH}(\mathrm{Ph})-\mathrm{Ar}), \quad 141.3-143.7$ (aromatic $\left.\underline{C}-\mathrm{CH}(\mathrm{Ar})_{2}\right)$, 143.7145.9 (aromatic $\underline{C}-\mathrm{C}\left(\mathrm{CH}_{3}\right)_{2}-\mathrm{Ar}$ ), 149.8-151.1 (aromatic $\underline{C}-$ $\mathrm{OH}$ reacted with benzaldehyde at two positions), 152.1-153.7 (aromatic $\underline{C}-\mathrm{OH}$ reacted with benzaldehyde at one position), 155.2-155.9 (aromatic $\underline{C}-\mathrm{OH}$ without any reactions).; FT-IR $\left(\mathrm{KBr}, \mathrm{cm}^{-1}\right)$ : $3504(-\mathrm{OH}), 3026$ (aromatic C-H), 2963 (aliphatic C-H), 1602 (aromatic C-C).

2-Naphthaldehyde-based Novolac (2). Yield: 9\% (reprecipitation with $\mathrm{THF} / \mathrm{methanol}) ;{ }^{1} \mathrm{H} \mathrm{NMR}\left(400 \mathrm{MHz}\right.$, THF- $d_{8}$, $\delta$ (ppm)): $0.80-1.55\left(\mathrm{Ar}-\mathrm{C}\left(\mathrm{CH}_{3}\right)_{2}-\mathrm{Ar}\right), \quad 6.00-6.40 \quad(\mathrm{Ar}-$ C $\underline{H}$ (Nap)-Ar), 6.40-8.20 (aromatic $H$ ).; ${ }^{13} \mathrm{C} \mathrm{NMR}(100 \mathrm{MHz}$, THF- $\left.d_{8}, \delta(\mathrm{ppm})\right): 29.5-33.8\left(\mathrm{Ar}-\mathrm{C}\left(\mathrm{CH}_{3}\right)_{2}-\mathrm{Ar}\right), 41.7-43.4$ (Ar- $\left.\underline{C}\left(\mathrm{CH}_{3}\right)_{2}-\mathrm{Ar}\right), 43.4-47.5$ (Ar- $\left.\underline{C} H(\mathrm{Nap})-\mathrm{Ar}\right), 115.0-116.4$, 124.6-126.9, 126.9-132.5, 132.6-133.8 (aromatic $\underline{C}$ without any functional groups, aromatic $\underline{C}-\mathrm{CH}(\mathrm{Ar})_{2}$ on a benzene ring), 133.8-135.5 (aromatic $\mathrm{C}-\mathrm{CH}(\mathrm{Ar})_{2}$ on a naphthalene ring), 141.4-144.9 (aromatic $\underline{C}-\mathrm{C}\left(\mathrm{CH}_{3}\right)_{2}-$ ), 151.1-156.2 (aromatic $\underline{C}-\mathrm{OH})$.

\section{RESULTS AND DISCUSSION}

\section{Synthesis of Bisphenol A Novolacs}

To prepare bisphenol A-based novolacs, unlike the previous report, ${ }^{6}$ 2-methoxyethanol was utilized as a reaction solvent because it was expected to be a good solvent for the hydroxyl group-containing substrate, propagation species and products. Addition-condensation of bisphenol A with benzaldehyde (feed ratio $=1: 2$ ) was carried out. A crude polymer (1) was obtained in $62 \%$ yield after reprecipitation with $\mathrm{THF} /$ water. Although reprecipitation of $\mathbf{1}$ was also carried out with $\mathrm{THF} /$ methanol, it was difficult to isolate the objective product. Polymer (1) was well-soluble in THF and acetone, but insoluble in chloroform and hexane.

The FT-IR spectrum of $\mathbf{1}$ showed peaks at $3504 \mathrm{~cm}^{-1}$ (hydroxyl group), $3026 \mathrm{~cm}^{-1}$ (aromatic $\mathrm{C}-\mathrm{H}$ bond), and $2962 \mathrm{~cm}^{-1}$ (aliphatic C-H bond) (Figure 1). The ${ }^{1} \mathrm{H}$ NMR spectrum of $\mathbf{1}$ indicated that each peak corresponded to a specific proton position (Figure 2). This suggested that $\mathbf{1}$ had a methine unit in the polymer backbone, which was derived from benzaldehyde. As shown in Figure 3, the ${ }^{13} \mathrm{C}$ NMR spectrum of $\mathbf{1}$ suggested that the main chain of $\mathbf{1}$ grew at the $\mathbf{3}$ and $\mathbf{3}^{\prime}$ positions on bisphenol A mainly. On the contrary, the condensation reaction at two positions on the same benzene ring, or no reactions on the benzene ring also proceeded

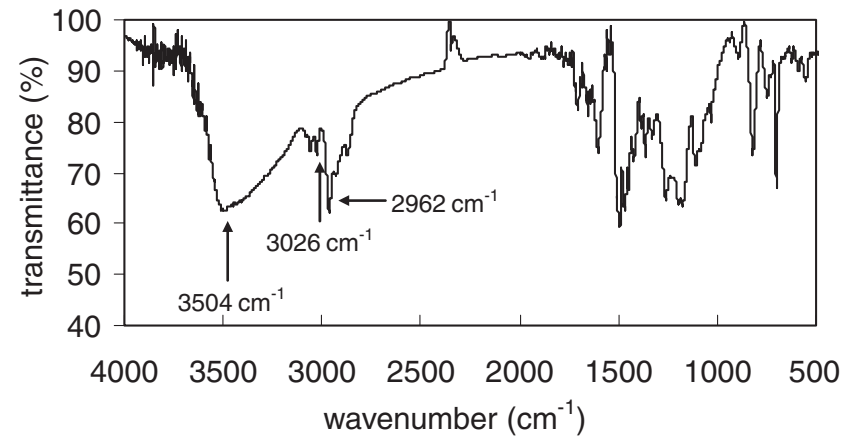

Figure 1. FT-IR spectrum of 1.

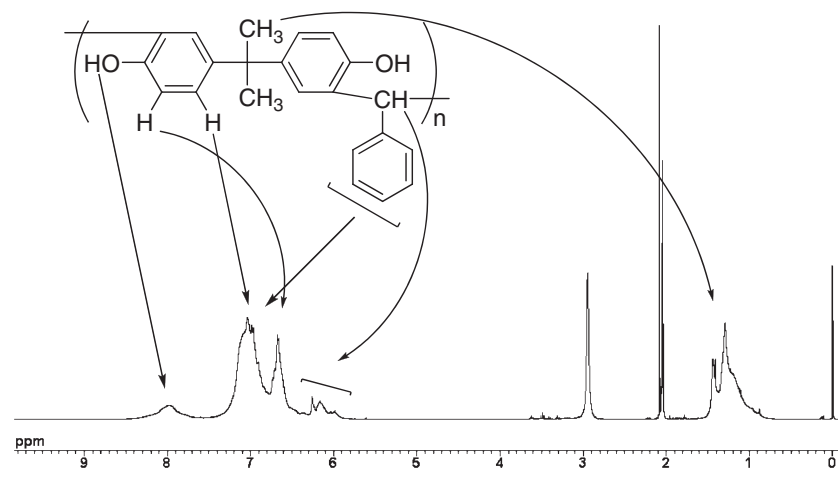

Figure 2. ${ }^{1} \mathrm{H}$ NMR spectrum of 1 in acetone- $d_{6}$.

(Figure 3, inset). These results indicated that the conformation of 1 was not only linear but also branching.

From GPC analysis, the number-average molecular weight $\left(M_{\mathrm{n}}\right)$ and the polydispersity index $\left(M_{\mathrm{w}} / M_{\mathrm{n}}\right)$ of $\mathbf{1}$ were found to be 23000 and 4.3, respectively. Because polymerization may proceed via fragmentation/re-combination of the phenylenemethylene bond, and the polymer has a branched structure, the value of $M_{\mathrm{w}} / M_{\mathrm{n}}$ of $\mathbf{1}$ became large. It was possible to calculate the degree of branching in the polymer backbone of $\mathbf{1}$, but this procedure was difficult because the aromatic proton peaks overlapped. On the other hand, when polymerization was carried out with a feed ratio of 1:1, the yield and the $M_{\mathrm{n}}$ and $M_{\mathrm{w}} / M_{\mathrm{n}}$ values of the obtained polymers were $38 \%, 2400$, and 1.6, respectively (Table I, run 2). Compared with run 1, all values decreased, indicating that the polymerization of bisphenol A and benzaldehyde was promoted by the increase in the benzaldehyde feed ratio via the formation of branching units.

In the next phase, polymerization of bisphenol $\mathrm{A}$ with a bulkier and more hydrophobic aldehyde, 2-naphthaldehyde, was carried out (Scheme 1, Table I, run 3). Polymer (2) was 


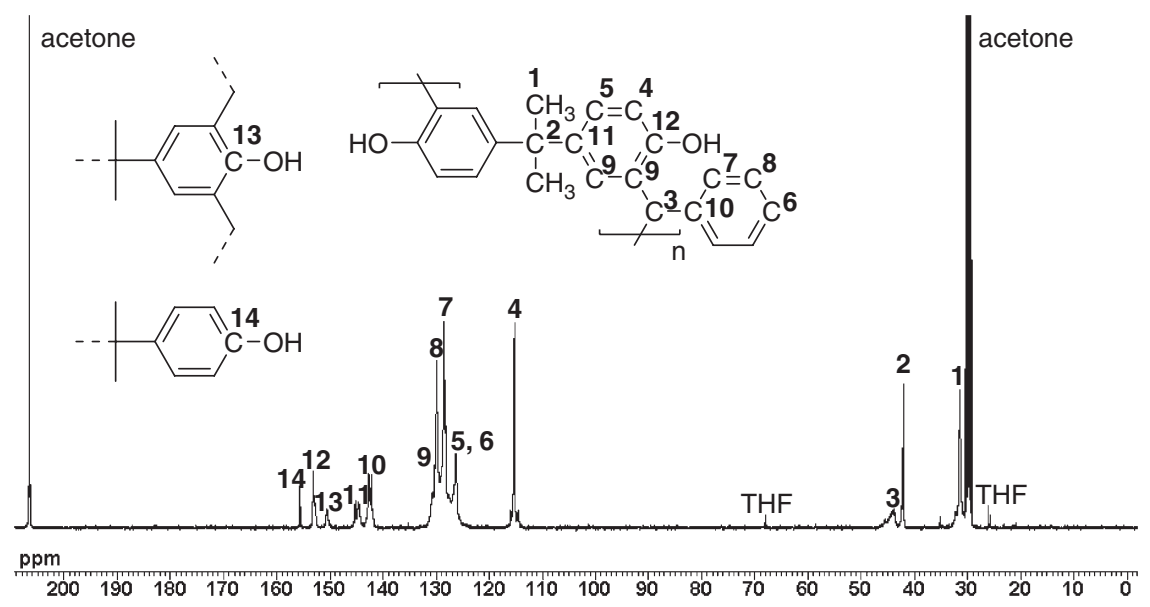

Figure 3. ${ }^{13} \mathrm{C}$ NMR spectrum of 1 in acetone- $d_{6}$.

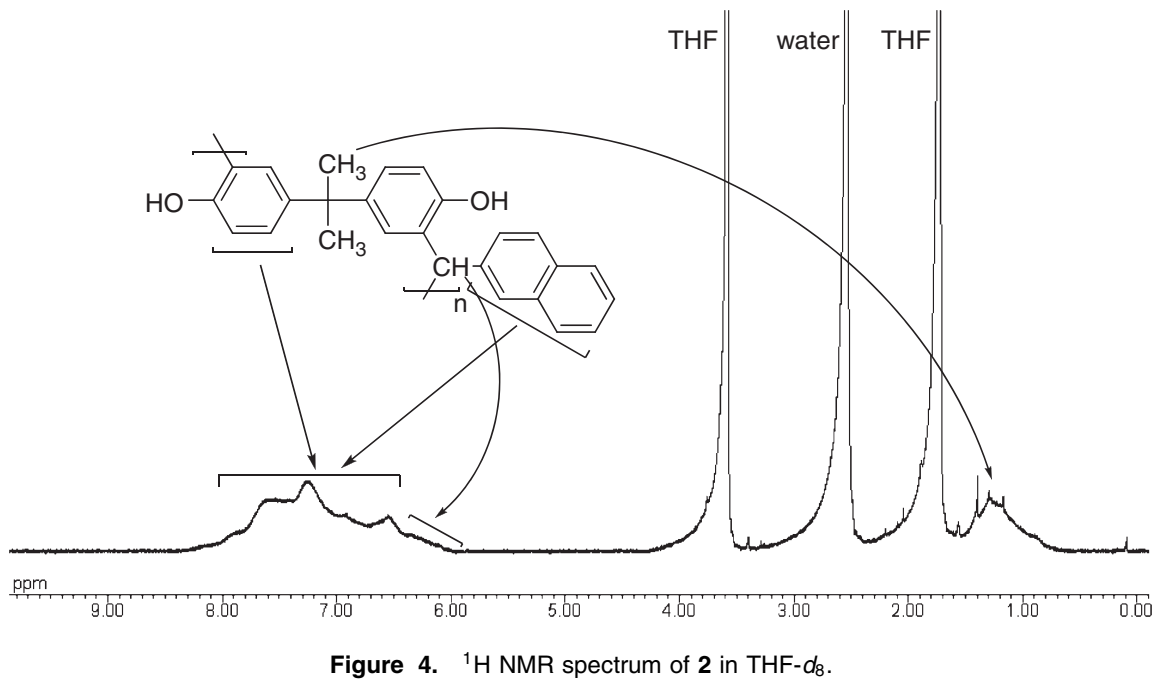

Table I. Addition-condensation of bisphenol A with various aldehydes

\begin{tabular}{lcccccc}
\hline run & aldehyde & $\begin{array}{c}\text { feed ratio } \\
\text { (substrate:aldehyde) }\end{array}$ & $\begin{array}{c}\text { time } \\
\text { (h) }\end{array}$ & $\begin{array}{c}\text { yield } \\
(\%)\end{array}$ & $M_{\mathrm{n}}{ }^{* 4}$ & $M_{\mathrm{w}} / M_{\mathrm{n}}{ }^{* 4}$ \\
\hline 1 & benzaldehyde & $1: 2$ & 2 & $62^{* 1}$ & $23000^{* 5}$ & $4.3^{* 5}$ \\
2 & benzaldehyde & $1: 1$ & 2 & $38^{* 1}$ & 2400 & 1.6 \\
3 & 2-naphthaldehyde & $1: 2$ & 2 & $9^{* 2}$ & 29000 & 1.7 \\
4 & 2-ethylbutylaldehyde & $1: 2$ & 24 & N.D. ${ }^{* 3}$ & - & - \\
5 & pivalaldehyde & $1: 2$ & 24 & N.D. ${ }^{* 3}$ & - & - \\
6 & formaldehyde & $1: 2$ & 1 & gelation & - & - \\
\hline
\end{tabular}

${ }^{* 1}$ : Isolated yield after precipitaion with THF/water. ${ }^{* 2}$ : Isolated yield after precipitaion with THF/methanol. ${ }^{* 3}$ : Not determined. ${ }^{* 4}$ : Measured by GPC (PSt, eluent: THF). ${ }^{* 5}$ : After rejection of the lower molecular weight by HPLC.

obtained in $9 \%$ yield after reprecipitation by $\mathrm{THF} /$ methanol. The values of $M_{\mathrm{n}}$ and $M_{\mathrm{w}} / M_{\mathrm{n}}$ were 29000 and 1.7 , respectively.

The ${ }^{1} \mathrm{H}$ NMR spectrum of $\mathbf{2}$ showed that the peaks of the methyl protons, methine proton and aromatic protons appeared at $0.80-1.55,6.00-6.40$ and $6.40-8.20$, respectively; however, it was difficult to estimate the number of branching units, the number of reacted positions on bisphenol A-benzene rings
(Figure 4). From the ${ }^{13} \mathrm{C}$ NMR spectrum (Figure 5), the peaks of $\mathrm{C}_{1}$ carbon at $151.1-156.2 \mathrm{ppm}$ indicated three types of moieties in the polymer backbone: non-substituted (156.2 ppm), mono-substituted (153.7 ppm), and di-substituted (151.1 ppm). This suggested that polymer 2 had a branching unit in the main chain to form a branched structure. The peaks observed were broad, and thus, the degree of branching could not be determined.

Although the yield of 2 was low (9\%) due to the low reactivity of naphthaldehyde, the product could be isolated by reprecipitation with THF/methanol, because of its solubility in organic solvents (hydrophobicity). In the case of $\mathbf{1}$, the hydrophobicity of the phenyl group from benzaldehyde is low, so the hydroxyl group plays the main role in the solubility of $\mathbf{1}$, showing the difficulty of reprecipitaion with THF/methanol. In contrast, 2 also included two different moieties in the side chain, the hydroxyl and naphthyl groups from the spectra of $\mathbf{2}$. The former is hydrophilic, while the latter is strongly hydrophobic; therefore, the hydrophobicity of $\mathbf{2}$ was stronger than that of 1, resulting in successful precipitation with THF/ methanol, and giving only a higher-molecular-weight product. 


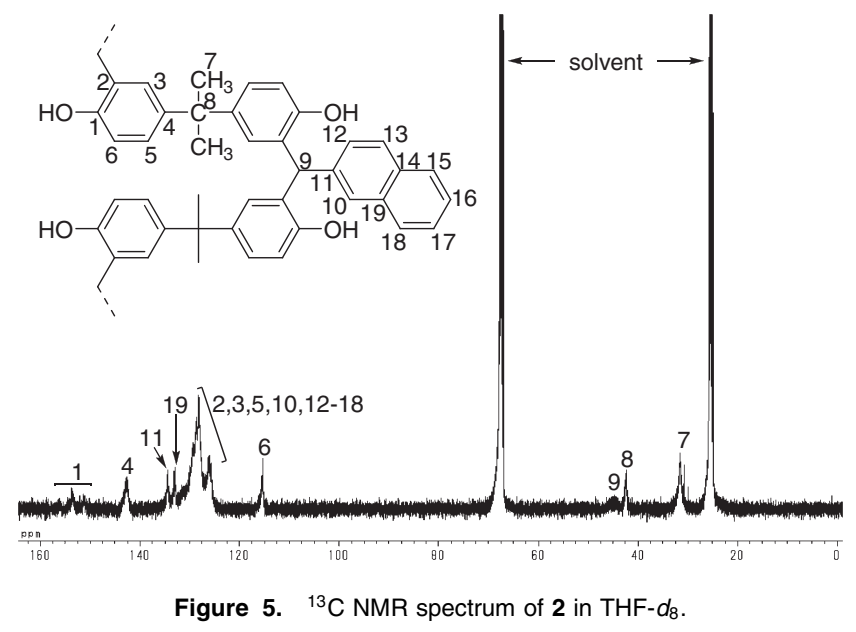

To examine the mechanical properties of polymers, thin films of $\mathbf{1}$ and $\mathbf{2}$ were prepared by spin-coating. This was difficult because of the inflexibility of the phenolic resins on the main chains, and compatibility between poly(bisphenol A carbonate) (Aldrich) and polymers $\mathbf{1}$ or $\mathbf{2}$ was not observed by dynamic scanning calorimetry (DSC) analysis.

Next, to investigate the influence of reactivity and the steric effect of an aldehyde on polymerization, we examined polymerization using aliphatic aldehydes (Table I, runs 4-6). Using 2-ethylbutylaldehyde (run 4) and pivalaldehyde (run 5), a polymer was not obtained even after the reaction solution was stirred for $24 \mathrm{~h}$. This was due to lower reactivity and larger steric hindrance compared with aromatic aldehyde. In contrast, in the case of using formaldehyde (run 6), polymerization could not be controlled to obtain a gel. This result indicated that the reactivity of carbocations from formaldehyde was so strong under this reaction condition that cross-linking reactions occurred.

\section{Thermal Properties}

The thermal properties of polymers $\mathbf{1}$ and $\mathbf{2}$ were examined by dynamic scanning calorimetry (DSC) and thermogravimetric analysis (TGA, Figure 6) in $\mathrm{N}_{2}$ flow. In the DSC charts of $\mathbf{1}$ and 2, no apparent glass transition points $\left(T_{\mathrm{g}}\right)$ were observed up to $200{ }^{\circ} \mathrm{C}$. This behavior was similar to conventional phenolic resins. Their temperatures at $5 \%$ loss in weight $\left(T_{\mathrm{d} 5}\right)$ were $156.6^{\circ} \mathrm{C}$ and $335.1^{\circ} \mathrm{C}$, respectively. The lower $T_{\mathrm{d} 5}$ value of polymer 1 was probably caused by its hydrophilicity, resulting from the presence of many hydroxyl groups. As shown in the chart of oligomeric phenolic resins (3) derived from phenol and formaldehyde, the weight decrease of $\mathbf{1}$ also started below $150{ }^{\circ} \mathrm{C}$ due to degradation around the phenolic hydroxyl groups. The $T_{\mathrm{d} 5}$ of polymer $\mathbf{2}$ was higher than that of $\mathbf{1}$ and $\mathbf{3}$, probably because of the aromaticity and hydrophobicity of $\mathbf{2}$. In the preparation of 2, 2-naphthaldehyde was used as an aldehyde component; accordingly, the obtained polymer was rich in the aromaticity from the naphthalene units. Furthermore, the size of a naphthalene unit on a methine moiety of $\mathbf{2}$ is larger than that of a benzene unit of $\mathbf{1}$ or that of a proton unit

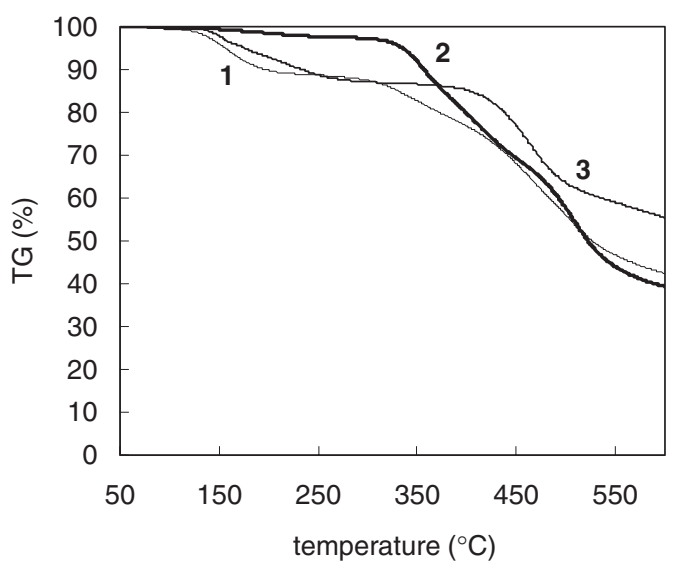

Figure 6. Thermogravimetric (TG) analyses of polymer 1 (solid line) and polymer 2 (bold line).

Table II. Solution properties of $\mathbf{1}^{\prime}$ and $\mathbf{2}$ in dilute THF solutions

\begin{tabular}{cccc}
\hline polymer & $M_{\mathrm{n}}{ }^{* 1}$ & $a^{* 2}$ & $\log K^{* 2}$ \\
\hline $\mathbf{1}^{\prime}$ & $2.1 \times 10^{6}$ & 0.41 & -3.4 \\
$\mathbf{2}$ & $1.9 \times 10^{5}$ & 0.43 & -3.5 \\
\hline
\end{tabular}

${ }^{* 1}$ : Measured by SEC-VISC-RALLS system. ${ }^{* 2}$ : Mark-Howink-Sakurada equation $\left([\eta]=K \mathrm{M}^{a}\right)$.

of 3; consequently, the hydroxyl group on bisphenol A was protected by a naphthalene unit and polymer $\mathbf{2}$ was a hydrophobic material which showed high thermal stability. ${ }^{5 \mathrm{~d}}$

\section{Solution Properties}

The solution properties of polymers $\mathbf{1}$ and $\mathbf{2}$ in dilute THF solutions were estimated using a SEC-VISC-RALLS system $\left(\right.$ Viscotek) ${ }^{8}$ (Table II). In order to perform a more accurate measurement, a higher-molecular-weight fraction $\left(\mathbf{1}^{\prime}\right)$ was separated by HPLC (the higher-molecular-weight fraction was estimated to be $3.2 \%$ in the crude product). The value of parameter $a$ in the Mark-Houwink-Sakurada equation $\left([\eta]=K \mathrm{M}^{a}\right)$ was 0.41 for polymer $\mathbf{1}^{\prime}$ and 0.43 for polymer 2. This indicated that these polymers can have compactly folded structures; moreover, it seemed from the amphiphilic property of THF that these polymers showed approximately the same values of $a$ despite the different solubilities in organic solvents mentioned above. Compared with conventional phenolic resins $(a \approx 0.3),{ }^{9,10}$ the values of $a$ were large and, as a result, polymers $\mathbf{1}^{\prime}$ and $\mathbf{2}$ may show good processability.

\section{CONCLUSIONS}

We successfully synthesized organosoluble high-molecularweight novolacs by addition-condensation of bisphenol A with aromatic aldehyde. The aromatic moieties on the side chain of the polymers seemed to exhibit hydrophobic properties and good solubility and, accordingly, the obtained polymers are expected to have high molecular weights. The ${ }^{13} \mathrm{C} \mathrm{NMR}$ spectrum suggested that these polymers had a branching 
structure in the polymer backbones. From thermogravimetric analyses, these polymers, particularly the benzaldehyde-based polymer, included significant water components within their networks via the hydrogen-bonding effect. These results suggest that the obtained polymers can be applied as organosoluble ion-exchange, thermostable, and water-supported resins using the hydroxyl group.

Acknowledgment. We thank Prof. Y. Nakamoto, Prof. T. Yamagishi, and Dr. H. Sue (Kanazawa University) for helpful discussion. This work was partially supported by Industrial Technology Research \& Development Grant (04A23030) from NEDO of JAPAN.

Received: August 28, 2008 Accepted: December 20, 2008 Published: February 12, 2009

\section{REFERENCES}

1. a) "Epoxy Resins," C. May, Ed., CRC press, 1987.

b) R. S. Bauer, "Epoxy Resins: Chemistry and Technology," American Chemical Society.

2. a) X. S. Wang, H. K. Kim, Y. Fujita, A. Sudo, H. Nishida, and T. Endo, Macromolecules, 39, 1046 (2006).

b) J. Choi, S. G. Kim, and R. M. Laine, Macromolecules, 37, 99 (2004).

c) H. Okamura, K. Shin, and M. Shirai, Polym. J., 38, 1237 (2006). d) L.-Y. Jia, C. Zhang, Z.-J. Du, C.-J. Li, and H.-Q. Li, Polym. J., 39, 593 (2007)

e) K. Yokomachi, M. Seino, S. J. Grunzinger, T. Hayakawa, and M. Kakimoto, Polym. J., 40, 198 (2008).

f) M. Ukaji, M. Takamura, K. Shirai, W. Gang, T. Yamauchi, and N. Tsubokawa, Polym. J., 40, 607 (2008).

g) L. Xue and Y. Kawakami, Polym. J., 39, 379 (2007).

h) Z. Ge, Z. Tao, J. Liu, L. Fan, and S. Yang, Polym. J., 39, 1135 (2007).
3. a) "Handbook of Polycarbonate Science and Technology," J. T. Bendler, Ed., Marcel Dekker, 1999.

b) H. Schnell, "Chemistry and Physcs of Polycarbonates," Interscience Publishers, 1964.

4. a) M. Stolka, J. F. Yanus, and D. M. Pai, J. Phys. Chem., 88, 4707 (1984).

b) S. Zhao, L. Zhang, W. Li, and L. Li, Polym. J., 38, 523 (2006).

c) S. Fukuoka, M. Tojo, H. Hachiya, M. Aminaka, and K. Hasegawa, Polym. J., 39, 91 (2007).

d) J. Mayumi, A. Nakagawa, K. Matsuhisa, H. Takahashi, H. Takahashi, and M. Iijima, Polym. J., 40, 1 (2008).

5. a) A. Knop and L. A. Pilato, "Phenolic Resins," Springer-Verlag, Berlin, 1985

b) G. Konishi, J. Syn. Org. Chem. Jpn., 66, 705 (2008).

c) T. Takeichi, T. Kawauchi, and T. Agag, Polym. J., 40, 1121 (2008).

d) T. Kimura, Y. Nakamoto, and G. Konishi, Polym. J., 38, 606 (2006).

e) A. Kobayashi and G. Konishi, Polym. J., 40, 590 (2008).

f) T. Nemoto, G. Konishi, T. Arai, and T. Takata, Polym. J., 40, 622 (2008).

g) J. Cui, Y. Yan, J. Liu, and Q. Wu, Polym. J., 40, 1067 (2008)

h) B. S. Kaith and S. Kalia, Polym. J., 39, 1319 (2007).

i) J. Jeerupan, G. Konishi, T. Nemoto, D.-M. Shin, and Y. Nakamoto, Polym. J., 39, 762 (2007).

j) D. Crespy, M. Bozonnet, and M. Meier, Angew. Chem., Int. Ed., 47, 3322 (2008).

6. G. Pan, Z. Du, C. Zhang, C. Li, X. Yang, and H. Li, Polym. J., 39, 478 (2007).

7. T. Nemoto and G. Konishi, Polym. J., 40, 651 (2008).

8. a) T. Nemoto, T. Ueno, M. Nishi, D.-M. Shin, Y. Nakamoto, and G. Konishi, Polym. J., 38, 1278 (2006).

b) T. Fukuoka, H. Uyama, and S. Kobayashi, Macromolecules, 36, 8213 (2003).

9. K. Kamide and Y. Miyakawa, Makromol. Chem., 179, 359 (1978).

10. a) S. Ishida, T. Kitagawa, Y. Nakamoto, and K. Kaneko, Polym. Bull., 10, 533 (1983).

b) H. Sue, Y. Nakamoto, and S. Ishida, Polym. Bull., 21, 97 (1989). c) H. Sue, E. Ueno, Y. Nakamoto, and S. Ishida, J. Appl. Polym. Sci., 38, 1305 (1989).

d) T. Yamagishi, M. Nomoto, S. Yamashita, T. Yamazaki, Y. Nakamoto, and S. Ishida, Macromol. Chem. Phys., 199, 423 (1998). 